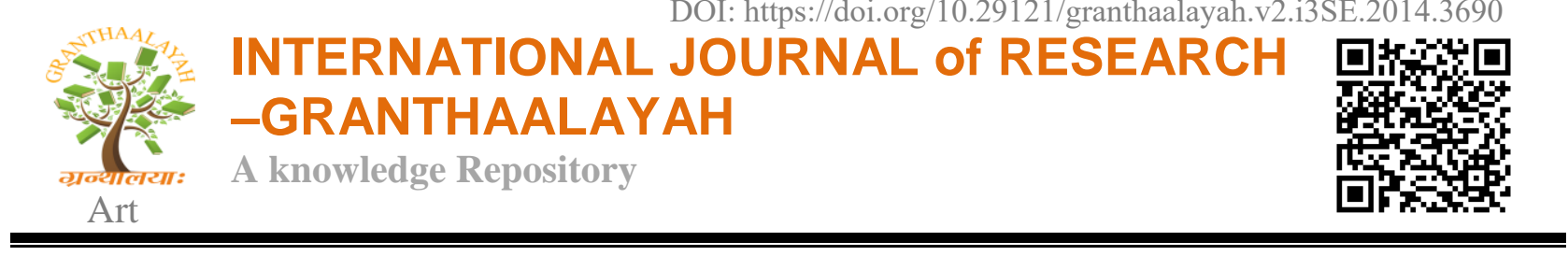

\title{
COLOR CONCEPTS IN WARDROBE PLANNING
}

Dr. Mrs Kirti Tewari

H.O.D- Dept of Home Science, M.L.B Girls P.G College, Kila Maidan. Indore

Fashion trends point out colors to wear but individuality should never be overlooked An impression of fine colors in dress will be gained if they are becoming to the person who is to wear them, if they are right for the occasion and if they are selected and arranged so as to make a pleasing ensemble. The larger the area the duller a color should be specially for business wear, but foe an evening or sports wear, it should be modified. The colors should be bright then, provided the wearer is not too large. The colors, in a costume, should be so distributed that a balance is achieved. When the top is light, the other part may be dark but the darkness should be present in the lighter area as a contrast. One should always keep in mind that the wearer should be the centre of interest and the costume a background.In order that the costume may be beautiful its color should be balanced or keyed and the entire color scheme should be related to the coloring of the individual.The aim in choosing colors for individual types should be to select those which will bring out the persons best points and subdue the less attractive ones.

Some of the factors influencing the choice of colors are the following:

- The effect of light/ Daylight or artificial.

- Texture of skin and hair.

- The age of the person.

- The size of the person.

- The personality characteristics.

- The complexion.

- The occasion.

As daylight is very much more brilliant and trying to the complexion than artificial light, colors need to be chosen more carefully for daytime wear. Colors selected for the evening wear should be seen by artificial light.A certain hue in a soft texture such as velvet, fur and wool is easier to wear than the same hue in the brilliant hardness of satin or lustrous velvet. Similarly, white organdy or linen worn near the face is becoming, while white satin, because of its sharp lights, is even more trying.Thin women should not choose fabrics that fall in long straight folds thus making them look thinner. They should use fabrics in light colors similar to soft taffetas which break into lines taking several directions and appear to increase their size.Older women should not wear such harsh bright colors as sharp blue and orange or purple.Since bright colors have a tendency to harden an older women's face, small amounts of these colors would be more appropriate. A woman who is stout and is of a good figure should choose low values which will give the appearance of reducing her size.People who lack color and have a quiet and retiring manner are eclipsed by large amounts of bright color, and are effaced by too much dull color. Dramatic persons can wear any colors which are becoming to them and suitable for the occasion.There are so many variations in individuals, and each spectrum hue has so many different effects through its three properties: Intensity, value and hue; that a mere table of colors will not solve the problem. Very light values seem to add color. If a person wishes to bring out the color in the complexion and hair, it would be advisable to wear white or some very light 


\section{INTERNATIONAL JOURNAL Of RESEARCH -GRANTHAALAYAH

value next to the face. Colors may force either their opposite or their neighboring hues; those colors should be chosen that will bring out the desirable hues in a person's complexion.Complementary colors force each other, so any desirable color in the complexion may be emphasized through their use. For example, a slightly rosey flush on the cheeks will be intensified by the use of the greenish color. On the other hand, if a person has any undesirable color in his complexion, he should avoid wearing the intense compliment of that color.The color of the hair, eyes or any color in the complexion can be emphasized through the repetition of the same hue. This may be accomplished by wearing the large amount of the same hue in a lower intensity than the color to be supressed or a small amount of the same hue in bright intensity.Colors affect each other and change a person's appearance. Thus a person is able to determine the best colors for any person and to suggest changes, such as color at the face to relieve harshness or the addition to the color note or value contrast that would transform an unbecoming garment into a becoming one.Women can solve some of their complexion difficulties by wearing makeup, but men do not take this advantage.Both however have some problems whose successful solution depends upon knowing how to use color.

Here are some golden rules: Wear colors that are neither too similar to the color of the skin nor too unlike it.

- Choose colors that are warm enough to be harmonious to the skin, yet are different enough in hue and value to give interest and variety.

- Avoid unrelieved black near the face.

- Avoid unrelieved tans and greys too near the value of the skin.

- Avoid colors in light or middle values in which yellow, yellow-orange, yellow- green predominate

- Avoid bright purples, red- purples, blue- purples or blues.

If in planning a wardrobe one adheres to a basic color, it will prove to be convenient since all of one's clothes will look well together.Furthermore it will be economical because fewer accessories will be needed.In working out such a plan, the first question is when to choose relative colors and when to use contrasts; second if contrasts are to be used, how they may be supplied; and third which garments should be selected for these contrasting accents. The size of the person will influence the choice between related and contrasting colors. A slender and well proportioned person may afford to break the length of the figure by the use of contrasting garment parts, but when this is done the color should be repeated at the neck.In this way the most striking effect becomes apparent, and the eye will gradually recognize the more subtle changes brought out by the different colors in the hair, eyes and complexion of the individual.

\section{REFERENCES:}

1 Grandis L.D. "Theory and use of color" Prentice Hall, Inc.

2 Craig H.T. and Rush O.D. "Homes with character" U.B.S Publishers Distributers Pvt. Ltd.

3 Goldstein and Goldstein "Avt in everyday life".

4 Rutt. A. Hong "Home Furnishing”. 